\title{
THE IDENTIFICATION OF LAND UTILIZATION IN COASTAL RECLAMATION AREAS IN TIANJIN USING HIGH RESOLUTION REMOTE SENSING IMAGES
}

\author{
Yunshan Meng*, Yingzhi Cao, Hongjun Tian, Zhicong Han
}

National Marine Data and Information Service, 300171, Tianjin, China-(mengys@1reis.ac.cn, ks721@163.com, 15668348@qq.com, 1820498296@qq.com)

KEY WORDS: Reclamation, High resolution images, Object-based classification, Decision tree method

\begin{abstract}
:
In recent decades, land reclamation activities have been developed rapidly in Chinese coastal regions, especially in Bohai Bay. The land reclamation areas can effectively alleviate the contradiction between land resources shortage and human needs, but some idle lands that left unused after the government making approval the usage of sea areas are also supposed to pay attention to. Due to the particular features of land coverage identification in large regions, traditional monitoring approaches are unable to perfectly meet the needs of effectively and quickly land use classification. In this paper, Gaofen-1 remotely sensed satellite imagery data together with sea area usage ownership data were used to identify the land use classifications and find out the idle land resources. It can be seen from the result that most of the land use types and idle land resources can be identified precisely.
\end{abstract}

\section{INTRODUCTION}

China is one of the most populous nations in the world with about 50 percent of the population lives in eleven coastal provinces and major cities (Duan H., 2016). Land reclamation from the sea becomes one potential solution for increasing demand of land resources for living and economic development. Based on historical statistics, it is estimated that a total area of 13 $380 \mathrm{~km}^{2}$ has been reclaimed between 1950 and 2008 in China (Wang W., 2014). Most of the reclamation regions were planned to be used for building ports and industrial zone, agriculture bases and costal urban town construction, scenic and recreation facilities, fishery industry. However, due to some human and natural causes, such as ineffective measures of attracting investment, the changes of state industrial policy, inadequate infrastructure in the new lands, or some other natural geological factors, like land subsidence, some of the regions were left unused after the Chinese government making approval the use of sea areas. In order to make rational use of reclamation resources, it is necessary to identify the utilization of coastal reclamation areas and investigate the areas and locations of the idle land resources, which can provide a feasible implementing scheme for decisions making in idle land resources reuse.

Based on the researches from the related references and though analysis (Suo A., 2016), we definite the idle land resources of reclamation area contents unfinished reclamation projects, no use or insufficient use reclamation land that could be easily recognized from remote sensing images, which can be reused for industries, urban and rural construction, salt- making industries and fishery industries. In this paper, we take Tianjin coastal area as an example, aim to classify the land utilization of coastal areas precisely with high spatial resolution remote sensing images, and identify the idle resource of land reclamation region in the study area together with the land use degree data and the sea area ownership database. The result of this work would be a good foundation study for guiding the coastal management.

\section{STUDY AREA}

Tianjin is a famous metropolis that located at the center of Bohai Rim Economic Zone of west Pacific Ocean, northeast of North China Plain, with a coastline of over $153 \mathrm{~km}$ according to the field investigation in 2005. The main human economic activities in coastal area of Tianjin are harbors constructions, oil and gas development, salt-making, scenic and recreation facilities, fishery industry and so on. Along with the enlargement of land space demand for the rapid development of economic activities, land reclamation projects are playing an increasingly important role in solving the shortage of land resources. The accumulative area of land reclamation has been reached $320 \mathrm{~km}^{2}$, while the length of artificial coastline has been increased from $41.16 \mathrm{~km}$ to $217.79 \mathrm{~km}$ by the end of January, 2014 (Wang Y., 2015).

The study area is located in Tianjin coastal area. As Fig. 1 shows, the reclamation area of the study region is practically covered by sea water, muddy water that containing sediment, roads and dams, bare area and areas used for industrial constructions.

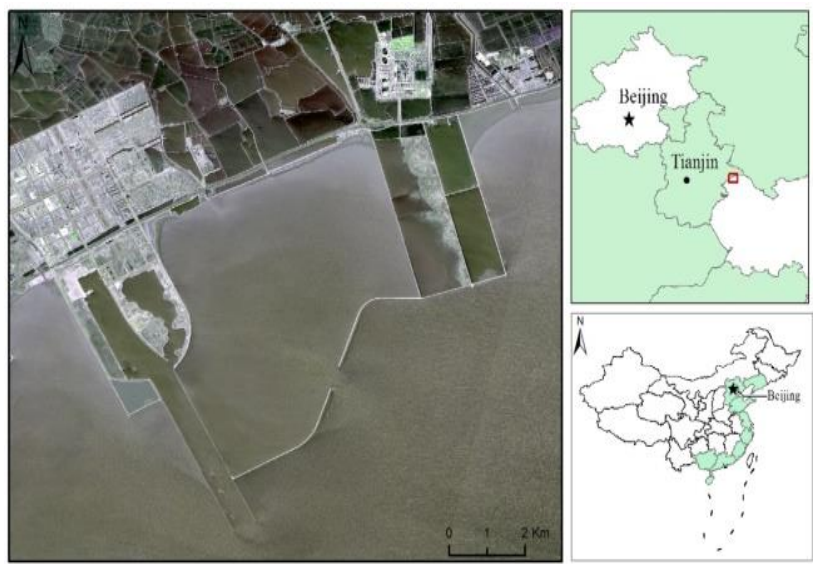

Figure 1. The location and the high resolution remote sensing image of the study area 


\section{DATA AND METHODS}

\subsection{Datasets}

High resolution remote sensing image that obtained from Gaofen-1 remotely sensed satellite (GF-1) was used in this study. This satellite sensor was launched in April 2003 in Jiuquan, China, and achieved a spatial resolution of 2 meters. The analysis of this high resolution image has already been extensively used in a lot of applications, such as dynamic land use and cover change, climate changes, precision agriculture, urban planning, coastline change detection, and so on. For the purpose of this research we acquired a standard geometrically corrected multispectral 4-band stereo data that taken in July 2017.

Ocean is rich in natural resources, including marine living, mineral resources and energy. Any entity and individual may, for the use of sea areas, apply to the department charge of marine administration under the people's government as or above the county level in China. The sea area ownership data used in this paper was generated from the dynamic monitoring system for national sea area. The main attribute information of the data includes the sea area use, units that using the sea, area, name of each project, the property owners and their address information, et al.

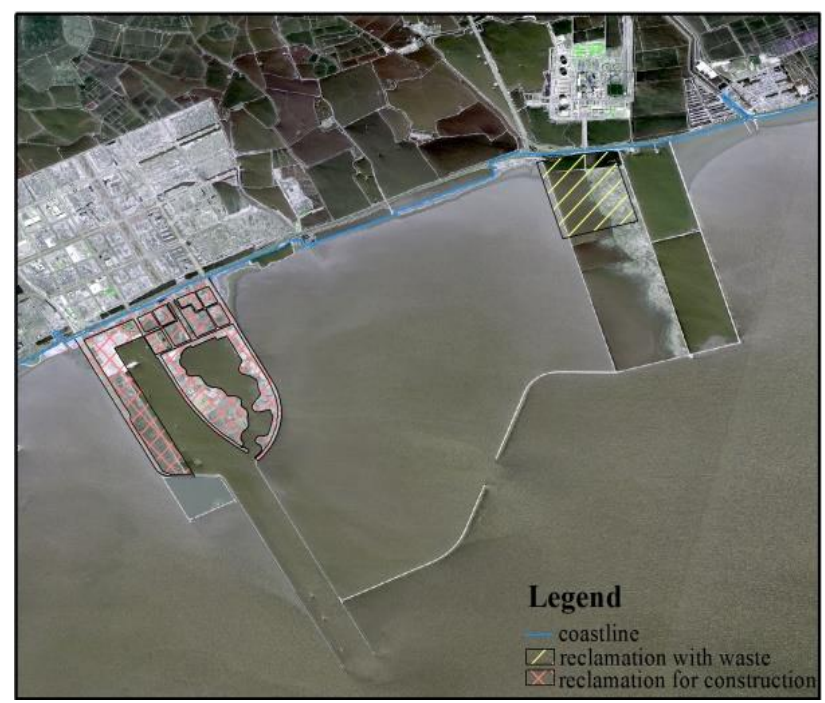

Figure 2. The sea area ownership data of the sea area

\subsection{Object-based classification}

In order to avoid the noise influences and make full use of the abundant texture and structure information that contained in the high spatial resolution remotely sensed satellite data, the objectbased classification technique was used in this research (Grant J., 2017). Firstly, the image pixels with similar spectral and texture features are clustered into meaningful objects before being classified. Through controlling the setting scale and homogeneity parameters, we performed a multi- resolution segmentation, in which clusters of pixels with similar spectral properties are iteratively aggregated so as to minimize heterogeneity. Then, the decision tree classification method was used to create the classification rules for distinguishing the land cover of the study area. The segmented data would be identified into several classifications by following the steps below:
Step1: On the first step we will define the preliminary classes and select the representative samples for each class. And then, classification rule sets will be established for the same surface target with significantly different spectral information respectively.

Step2: Due to obviously spectrum difference between nearshore water and off-shore water generated by sand and other sediment concentration, the sea area was identified into two classifications. According to the characteristic of each land cover, the segmented data was classified into 5 land use types, water, water containing lots of sediment, reclamation land for construction, dam and embankment road, and the unused area.

Step 3: if it were necessary, the reclamation land would be divided into construction area for industries, urban - rural respectively, and the water would be divided into sea and fishery water according to their geometry information of the segmented data.

The classification results of the reclamation area are shown in figure 3 bellow.

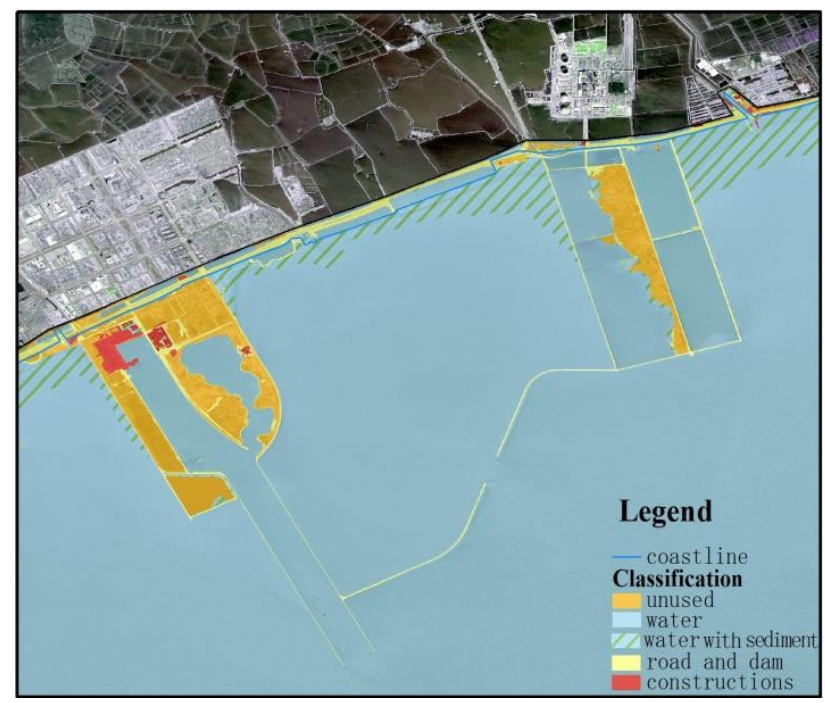

Figure 3. The classification result in the coastal reclamation areas by Object-based classification method

\subsection{Accuracy assessment of the result}

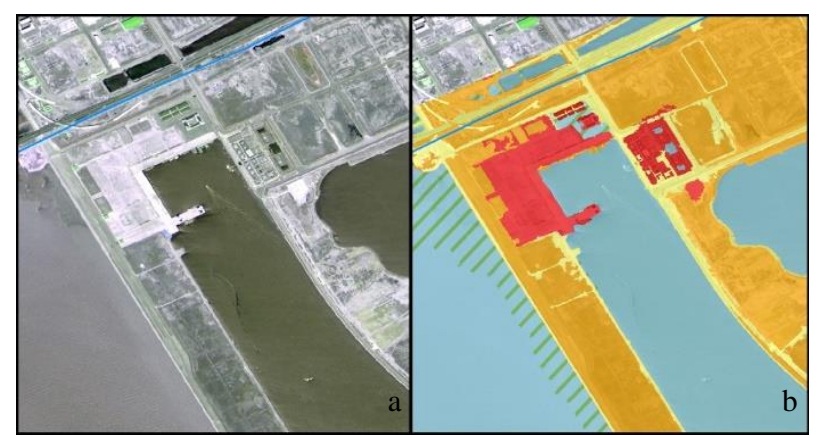




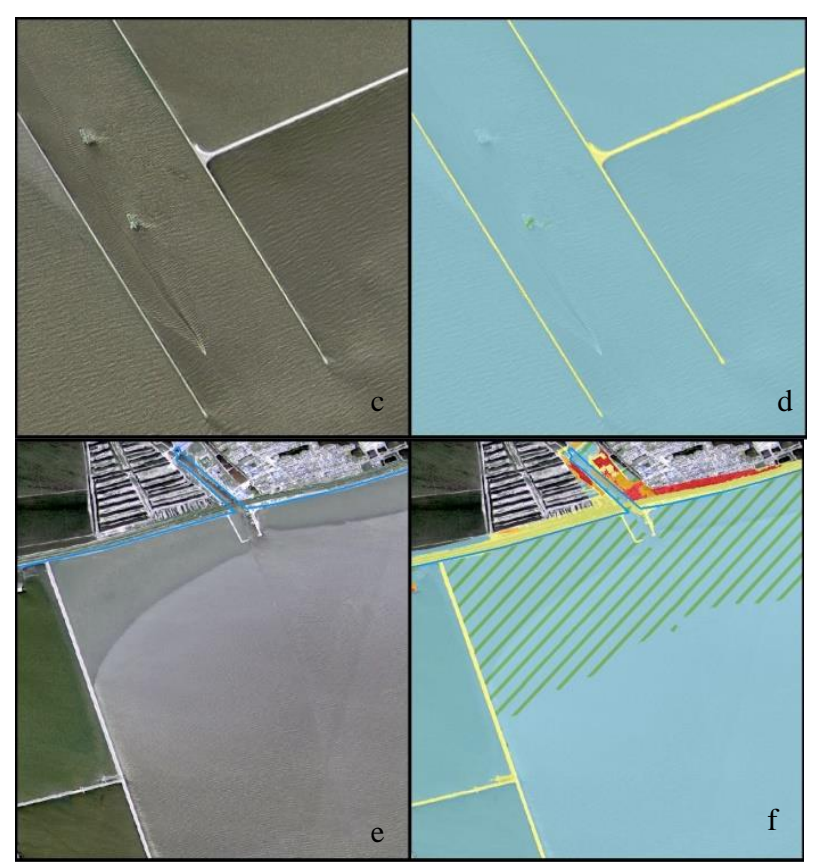

Figure 4. The comparison between ground truth of several regions and their classification results

As showed in fig.4, artificial structures were featured by high brightness and distinct edges in the remotely sensed imagery data, which makes them easily to be precisely segmented and recognized from other land coverage. In addition, the result of roads and dams identification can achieve very high accuracy, due to their special geometry information extracted from the segmentation data. Experimental results, especially the local classification details, indicate that our method can produce an ideal classification effect in this study area.

\section{RESULT}

As can be seen from the fig.2, the government authorized two sea area use projects in this sea area, which were intended to be used for construction reclamation land and reclamation with waste disposal respectively. According to the classification result, the filling work of the sea area that used for waste disposal has been finished for about 41.5 percent. Meanwhile, the filling work of the sea area that planned to be used for construction has almost been finished, however, construction areas only account for about 15.6 percent of the whole reclamation areas. The construction density is relatively low. And so, by definition, the unused area and the unfinished project were belonging to idle land that need for attention by relevant units.

\section{CONCLUSION}

Because of the effects by natural and human factors, some of the sea reclamation areas were left unused after the Chinese government making approval the usage of sea areas. Hence, in order to facilitate sea area and land resource administration, it is meaningful to effectively and efficiently identify the areas and distributions of coastal idle lands. In this paper, the experimental results with GF-1 remotely sensed imagery data sets and sea area usage ownership data showed that by processing the high resolution image based on object based classification method, the result can meet the requirement for idle land resource assessment. In the next step of our work, more land coverage types distinguish such as fishery area and green field will be considered in appropriate study region to perfect the method system.

\section{REFERENCES}

Duan H., Zhang H., Huang Q., Zhang Y. and Hu M., 2016. Characterization and Environmental Impact Analysis of Sea Land Reclamation Activities in China. Ocean \& Coastal Management, 130, pp. 128-137.

Grant J., Matthew R., William A., 2017. Training Deep Convolutional Neural Networks for Land-Cover Classification of High-Resolution Imagery, IEEE Geoscience and remote sensing letters, 14(4),pp. 549- 553.

Suo A., Wang P., Yuan D., Yu Y. and Zhang M., 2016. Study on morning and analysis of existing sea reclamation resource based on high resolution satellite remote sensing imagery: A case in south coast of Yingkou. Haiyang Xuebao, 38(9), pp. 54-63, doi: 10.3969/j.issn.0253-4193.2016.09.006.(Chinese)

Wang W., Liu H., Li Y. Q., Su J. L, 2014. Development and management of land reclamation in China, Ocean \& Coastal Management, 102: 415-425.

Wang Y., Shi H., Zhao X. and Yan W., 2015. Impact of Reclamation on water exchange in Bohai Bay in Recent decade, Oceanologia et Limnologia Sinica, 46(3), pp. 471-480. (Chinese) 